Revista Iberoamericana, Vol. LXXI, Núm. 212, Julio-Septiembre 2005, 801-814

\title{
EL ESPACIO RELACIONAL/LAS RELACIONES ESPACIALES: LA PRÁCTICA DEL FEMINISMO CHICANO EN LA LITERATURA FRONTERIZA CONTEMPORÁNEA
}

POR

\author{
MiCHELLE JofFroy \\ Smith College
}

En el nuevo milenio el lenguaje de la globalización está por todos lados -influye en nuestra comprensión de las relaciones económicas, políticas, ecológicas y culturales, e insiste en una nueva evaluación de las críticas culturales de la "vieja economía.” Ha sido central a muchos de los debates de la globalización del Estado y su destino en una época en la que vemos la disolución de los ejes nacionales hegemónicos. Hasta la crítica feminista no ha podido escapar de la red discursiva en torno a la globalización, por lo que se ha visto necesitada de desarrollar estrategias y modelos nuevos para dialogar con las fuerzas de la globalización y en algunos casos para contradecirlas. ${ }^{1}$ Para críticos y teóricos cuya investigación enfoca la producción cultural en varias zonas fronterizas, las cuestiones relativas a la globalización no presentan temas ni agendas innovadores de por sí. Desde la perspectiva de los productores y los consumidores de las “culturas fronterizas”, las cuestiones de la identidad nacional, la soberanía, la ubicación geográfica, y la distribución del poder político y económico constituyen condiciones materiales cotidianas en las que transactan los sujetos híbridos y multiculturales. ${ }^{2}$ Las feministas fronterizas, cuya praxis se funda en el activismo político e intelectual, en las últimas dos décadas han participado en conversaciones sobre los feminismos internacionales y su afiliación a un movimiento estadounidense feminista compuesto de las clases privilegiadas. En este ensayo el término “fronterizo/a” funcionará como traducción de "borderlands” y servirá para enfocar un espacio o una región en la que se encuentran los "límites” nacionales. El intento es

\footnotetext{
${ }^{1}$ Dos textos iluminadores sobre el feminismo y los debates del globalismo son Situating the Self: Gender, Community and Postmodernism in Contemporary Ethics de Seyla Benhabib y Scattered Hegemonies: Postmodernity and Transnational Practices editado por Inderpal Grewal y Caren Kaplan.

${ }^{2}$ Véase los siguientes estudios/ensayos para discusiones sobre la producción cultural en la zonas fronterizas de México, los Estados Unidos y América Latina: Criticism in the Borderlands: Studies in Chicano Literature, Culture, and Ideology editado por Héctor Calderón y José Saldívar; Mujeres y Fronteras: Una perspectiva de género, de Socorro Tabuenca Córdoba; The New World Border: Prophecies, Poems, and Loqueras for the End of the Century, de Guillermo Gómez-Peña; Border Writing: The Multidimensional Text, de Emily Hicks; Woman Singing in the Snow: A Cultural Analysis of Chicana Literature, de Tey Diana Rebolledo; The Dialectics of Our America: Genealogy, Cultural Critique, and Writing History, de José David Saldívar.
} 
imaginar esta región en términos más ámplios que trasciendan un enfoque en la línea divisora "oficial”.

A manera de acto contestatario y oposicional, las críticas chicanas y latinas han articulado varias versiones de un feminismo chicano/latino que emerge de sitios específicos de luchas “locales,” y que simultáneamente intenta establecer alianzas teóricas y materiales con los llamados "feminismos globales". Recientemente, la teoría del feminismo "transfronterista” de Sonia Saldívar-Hull ha intentado articular el perfil de un feminismo fronterizo local que reconoce e integra las realidades geopolíticas de la región fronteriza mexicana/estadounidense, en discursos de políticas étnicas, raciales, sexo-genéricas y socioeconómicas que se extienden por toda América Latina.Ya en 1987, la teoría de la nueva mestiza, propuesta por Gloria Anzaldúa en su exitoso libro Borderlands: La Frontera, y más tarde en 1991 las propuestas teóricas de una “consciencia oposicional”, o bien una "consciencia diferenciada" de Chela Sandoval, constituyeron modelos de feminismos latinos que vertieron luz sobre las relaciones globales entre las "mujeres de color" estadounidenses y otros movimientos feministas del tercer y el cuarto mundo. Según Sandoval, el feminismo transnacional hace posible la construcción de un "pueblo internacional/desnacional” habitado por "mujeres de color” cuyas identidades están ligadas no por la geografía compartida, sino por una compartida ubicación “en conciencia”; por los comunes terrenos síquicos y espirituales resultantes de parecidas experiencias del colonialismo (355). ${ }^{3}$ En conjunto, las teorías de Saldívar-Hull, Anzaldúa y Sandoval componen una intricada narrativa local y experiencial de la transformación social a un nivel teórico y arraigado en las fronteras geográficas norte/sur, tanto reales como imaginadas en la encrucijada del activismo cultural y político en los Estados Unidos y América Latina. Del intersticio de estos modelos dialogantes, emerge la proposición teórica de lo que llamaré en este ensayo "la práctica literaria de un feminismo chicano locacional o posicional”. Me propongo delinear y hacer patente la tensión inherente entre las especificidades de la experiencia local y las presiones de experiencias compartidas globalmente en relaciones dadas del poder global y local. Demostraré cómo tales prácticas feministas se articulan y registran en un nivel literario como parte del imaginario cultural feminista en el cuento "El pavo" de Alicia Gaspar de Alba, de su colección The Mystery of Survival (El misterio del perdurar) publicado en 1993. El cuento inscribe un feminismo fronterizo con una sutilmente matizada conciencia que simultáneamente afirma la realidad de la región fronteriza estadounidense y a la vez resiste la homogeneización de una América Latina monolítica, apuntando así a los paradigmas teóricos del feminismo "local/ global” y sugiriendo una reorientación de éste según las geografías específicas de la región fronteriza, caracterizada tanto por la hibiridez como por las identidades y los espacios liminales.

TEORÍAS LOCALES Y GLOBALES

La tensión interna de terrenos yuxtapuestos -una imaginada transnacionalidad global en conflicto con la materialidad de una geografía compartida-anima y modula la ejecución

\footnotetext{
${ }^{3}$ Las traducciones de los textos críticos escritos en inglés son mías.
} 
de un feminismo chicano locacional/posicional, revelando los conflictivos deseos de situar y fijar lo "local” y a la vez de traspasar fronteras hacia lo "global”. Por un lado, Chela Sandoval argumenta que los feminismos transnacionales realizan un "trastorno geopolítico" del Estado y sus imaginarios sociales (355), por el cual crean un nuevo espacio en el que se logra la ciudadanía plena y en el que se realiza la auto-determinación. Sandoval, con su contribución de una “conciencia en oposición”, sobre la cual se establecen los feminismos transnacionales, posibilita la forjación de una nueva conciencia en la que las diferencias no sólo se toleran, sino que se reconocen plenamente, y por la cual distintos movimientos sociales oposicionales pueden alinearse en coaliciones políticas. Tal consciencia "trans" permite la producción de un imaginado espacio de experiencia común que sustituye o desplaza las fronteras e identidades nacionalistas tradicionales primermundistas.

La “conciencia oposicional” de Sandoval proyecta y afirma la conciencia de la nueva mestiza teorizada por Gloria Anzaldúa:

\begin{abstract}
La nueva mestiza...tiene una personalidad plural, funciona de un modo pluralístico nada echado fuera, ni lo bueno, ni lo malo, ni lo feo, nada rechazado, nada abandonado. No sólo sostiene las contradicciones, transforma la ambivalencia en algo nuevo. Ese punto focal, o fulcro, esa coyuntura donde se para la mestiza, es donde los fenómenos tienden a chocar. Es el lugar donde ocurre la posibilidad de unificar todo lo que se considera separado. Al intentar realizar una síntesis, el ser ha añadido un tercer elemento que vale más que la suma de sus partes destrozadas. Ese tercer elemento es una nueva conciencia -la conciencia mestiza- y aunque significa un dolor intenso, su energía proviene del continuo movimiento creativo que sigue rompiendo los aspectos unitarios de cada nuevo paradigma. (101-02)
\end{abstract}

Vista a la par del aparato teórico de Sandoval, la nueva conciencia mestiza que propone Anzaldúa resume la agenda política de los feminismos transnacionales en su articulación de puntos de resistencia específicos hacia las jerarquías sociales estadounidenses. En las zonas fronterizas de los Estados Unidos y México, la nueva mestiza de Anzaldúa identifica estas jerarquías sociales y produce tácticas para la transformación social desde una postura oposicional. Ambas críticas-Sandoval y Anzaldúaproponen modelos teóricos feministas para la liberación social, política y cultural, localizados en un espacio imaginado y construido más allá de las fronteras de identidades nacionales, género-sexuales, sexuales, culturales y raciales. Este espacio "trans” se entiende como el sitio de la actualización de una práctica feminista radicada en las alianzas múltiples y variables forjadas a base de experiencias comunes compartidas, en vez de basarse en una geografía compartida. A pesar de que provienen de variadas y específicas "localidades" de opresión, estos feminismos transnacionales/globales teorizan la trascendencia de la "localidad” y abogan por la construcción de identidades y alianzas más allá de tal "localidad”.

Si la realidad de una geografía compartida complica sutilmente las posibilidades prácticas de un espacio "trans" completamente nuevo, la teoría del feminismo "transfronterizo” de Sonia Saldívar-Hull representa un intento de situar las trayectorias globales de Sandoval y Anzaldúa en localidades geográficas específicas. Al desarrollar la estructura crítica de su teoría transfronterista, Saldívar-Hull hace referencia específica a 
los papeles sociales y políticos de feministas chicanas y sus relaciones con feministas latinoamericanas y tercermundistas:

\begin{abstract}
Ahora puedo llamarme una intelectual chicana feminista -una mujer tercermundista criada en la periferia del Primer Mundo, en la zona fronteriza del sur de Texas. Uso el feminismo tercermundista para indicar cómo nuestras historias de chicanas/latinas nos fuerzan a examinar tanto la geopolítica como la política género-sexual. Como indica nuestro alineamiento con mujeres tercermundistas, nuestra ubicación como sujetos existe en los intersticios de las fronteras nacionales. Más específicamente, nos aliamos como mujeres cuyas necesidades específicas han sido mayormente ignoradas tanto por la mayoría de nuestros teóricos masculinos como por muchas feministas euro-americanas. Actualmente nos comprometemos con gente cuyas experiencias reflejan las nuestras.
\end{abstract}

Aunque la teoría del feminismo transfronterista se ocupa de la transgresión de fronteras de toda índole -las fronteras sexo-genéricas, geopolíticas, literarias, académicas e institucionales-, el concepto fundamental es ubicuo y posicional: emerge de una ubicación precisa y se enfoca en ella. Al respecto, Saldívar-Hull argumenta, ”mi formulación de 'feminismo fronterizo' se dirige a las formas en que el feminismo chicano participa en 'la frontera' [enmarcada] entre el feminismo anglo-americano y el latinoamericano, y a la misma vez, al lado de los feminismos de otras mujeres de color en los Estados Unidos" (56). A la vez que imagina alianzas a través de fronteras nacionales e institucionales -en cierta forma, dando eco al llamado transnacionalismo de Sandoval- Saldívar-Hull insiste en un compromiso con historias locales específicas. En contraste a la visión mitopoética de Anzaldúa, de una nueva mestiza que proviene de la "herida abierta" de la frontera estadounidense/mexicana, pero que se auto-construye en un espacio que trasciende de fronteras, el feminismo transfronterista reclama un espacio definido por la frontera como origen y ubicación de un feminismo chicano, experiencial y existencial específico. Es esta insistencia, precisamente, en lo local, en la posicionalidad, en la lucha entre lo local y lo global, que se articula tan urgentemente en la literatura contemporánea de chicanas en la zona fronteriza. ${ }^{4}$

\title{
GeOgRAFÍAS LOCALES/GLOBALES
}

Mientras que los numerosos fenómenos que componen la globalización se han caracterizado como amenazas que interrumpen espacios locales fijos, para la mayoría de la gente "la vida cotidiana sigue transcurriendo dentro de localidades bastante restringidas" (McDowell 3). ${ }^{5}$ De hecho, como argumenta Linda McDowell, "el resultado de todos esos

\footnotetext{
${ }^{4}$ Demetria Martínez, Sandra Cisneros, María Helena Viramontes, Rosario San Miguel y Rosina Conde son algunas de las autoras que trabajan cuestiones específicas a la zona fronteriza de México y los Estados Unidos.

${ }^{5}$ Linda McDowell pertenece a una nueva escuela de la geografía feminista que pone en tela de juicio la práctica tradicional de la geografía que ignora las condiciones materiales que afectan la constitución del espacio. Vease Feminism and Geography: The Limits of Geographical Knowledge,
} 
cambios bajo el término "globalización" no es que el mundo se convierta en una unidad, en la que se reducen las diferencias locales, sino que la 'diferencia'...es producida... paradójicamente de las mismas condiciones que las de los cambios globales” (3). Por cierto, esta versión de la globalización como distintas fuerzas que "reconstruyen en vez de destruir los espacios locales” ha permitido una lectura más sofisticada de la idea de la “localidad” en sí:

La común noción geográfica del "lugar" como una unidad de coordenadas en un mapa que fijan y definen un territorio, se ha puesto en tela de juicio. Los geógrafos ahora argumentan que los lugares son disputados, fluídos y variables. Son las prácticas socioespaciales las que definen los lugares y éstas resultan en espacios que intersectan y que se sobreimponen mediante límites múltiples y cambiables, constituidas y mantenidas por las relaciones de poder que construyen las reglas y definen los límites. (McDowell 4)

Las antropólogas feministas han postulado semejantes interpretaciones de lo que es un "lugar," bajo la denominación de "la naturaleza relacional del espacio" (5). También han argumentado que los espacios son definidos, mantenidos y alterados por medio del impacto de relaciones de poder desiguales. Judith Okely mantiene que "diferentes grupos que habitan los mismos espacios pueden crear y alterar los límites de éstos por medios sutiles” (3). Tanto la exclusión legal como la social definen el espacio, al igual que lo hace la dinámica cultural del distanciamiento social. Dicho distanciamiento no siempre implica la distancia geográfica, por lo cual se argumenta que "habitantes del mismo espacio cartesiano ocupan distintos 'lugares"” (McDowell 5). Los “lugares” a los cuales se refiere McDowell se determinan mediante los parámetros sociales, políticos y culturales que se le imponen al individuo - tal como son identidades nacionales, de clase, de género, de edad- y que configuran la experiencia del espacio y de la realidad. Estos espacios relacionales -localidades construidas mediante relaciones sociales entre grupos e individuos- se escurren por una escala espacial, según postula McDowell, y ahí es precisamente donde se puede comenzar a imaginar la experiencia del espacio y la construcción de lugares en la zona fronteriza.

El modelo binario de una dicotomía “local/global” presupone una relación estática proveniente de un significado esencial de los términos en sí. Esto presenta un esencialismo engañoso, sin embargo, precisamente porque la invocación de los términos históricamente se ha basado en imperativos políticos y culturales. Si en un espacio histórico particular, por ejemplo el México colonial, lo “local” se invocaba para defender la soberanía nacional ante la hegemonía europea, en los recientes eventos en la selva La Candona el término "local” significa esas culturas indígenas sistemáticas e históricamente silenciadas y marginalizadas por un gobierno centralizado "nacional”. Al mismo tiempo, en el caso de los feminismos globales y transnacionales -como por ejemplo el movimiento feminista tercermundista-vemos una reacción a ciertas fuerzas históricas que hacen posible alianzas femeninas a través de nuevos ejes de identificación que trascienden las identidades locales o nacionales. Los anteriores ejemplos sirven para subrayar la fluidez y la naturaleza

de Gillian Rose y Mapping the Subject: Geographies of Cultural Transformation, editado por Gillian Rose y S. Pile para discusiones comprensivas de este campo. 
variable de los términos mismos, tanto como su susceptibilidad a las cambiables condiciones históricas, políticas y culturales. ${ }^{6}$ Los términos “local” y "global” representan espacios discursivos definitivos para la realización de identidades políticas y culturales, y mientras siguen siendo un elemento central de la crítica feminista fronteriza deben ser también objetos del análisis crítico. Más adelante examinaré cómo, en el cuento de Alicia Gaspar de Alba, los conceptos de lo local y lo global se explotan delicadamente mediante una sensibilidad aguda de la geografía de los espacios locales fronterizos.

Tanto las fronteras nacionales como las personales, observa Susan Stanford Friedman, "se han vuelto más y más permeables ante los cambios rápidos que caracterizan los terrenos culturales y los panoramas globales” (3). No obstante, en el caso de los Estados Unidos y México, esta experiencia de la permeabilidad e inestabilidad de límites representa una constante histórica y no el resultado o respuesta a cambios globales contemporáneos. Las identidades nacionales en la zona fronteriza de los Estados Unidos y México históricamente se han forjado sobre la base de límites que fluctúan, que se disuelven y que se re-inscriben. ${ }^{7}$ Las cartografías de identidad nacional en la zona fronteriza lógicamente interpelan cuestiones de la identidad género-sexual y sus propias fluctuaciones y reconfiguraciones culturales como respuesta a la variabilidad de esta geografía. Una práctica feminista locacional/posicional, "basada no en definiciones estáticas y abstractas sino en la premisa de especificidades históricas y geográficas" (Friedman 5) -tal como las prácticas delineadas por Saldívar-Hull, Anzaldúa y Sandovalenfatiza tanto la fluidez de la ubicación geográfica, como la inestabilidad de los roles género-sexuales en la zona fronteriza.

La zona fronteriza estadounidense/mexicana y sus comunidades migratorias -tanto en el lado estadounidense como en el lado latinoamericano- reclama un espacio central en las obras narrativas de Alicia Gaspar de Alba. Cordelia Candelaria comenta en el ensayo introductorio de la colección The Mystery of Survival, "Gaspar de Alba sitúa su prosa narrativa corta en una localidad central -la Frontera, normalmente la frontera entre los Estados Unidos y México, pero también en las fronteras culturales que dividen a la gente americana” (3). El cuento "El pavo," de esta colección, es un ejemplo conmovedor de cómo se complica y problematiza el espacio fronterizo cuando una escritora enfoca la atención a múltiples nociones de la frontera en sus varias manifestaciones experienciales e imaginarias. Centrándonos en ese modo de ver particular -ese enfoque plural, híbrido y múltiple-cabe preguntarnos ¿cómo se relacionan los conceptos de “frontera,” "lo local”, y “lo global” en la zona fronteriza, mediante una práctica feminista locacional/posicional, según la imagina Gaspar de Alba?

\footnotetext{
${ }^{6}$ Reyes Lázaro, cuya investigación enfoca las retas al nacionalismo en la literatura española contemporánea, con un énfasis en las zonas fronterizas del país, ha contribuido a la articulación de este análisis de la terminología.

${ }^{7}$ Véase The Aztec Palimpsest: Mexico in the Modern Imagination de Daniel Cooper-Alarcón para un análisis excelente de la historia "geográfica/imaginaria" de la zona fronteriza.
} 
LA GEOGRAFÍA DEL ESPACIO Y LA REALIZACIÓN DE LOS ROLES GÉNERO-SEXUALES EN “EL PAVO”

“El pavo” es uno de once cuentos en su mayor parte bilingües que, como la mayoría de éstos, explora las relaciones tenues en una familia radicada en la zona fronteriza del sur de Texas. ${ }^{8}$ En este cuento se narran los eventos de la tarde que precede la celebración de “Thanksgiving”/Acción de Gracias en las vidas de Gabriela, la protagonista pre-adolescente de unos diez u once años, su padre Pepe y su abuelo viudo, Elías.

El conflicto central emerge del espacio y el momento en que el cuento transcurre: la inminente celebración de "Thanksgiving” y las expectativas impuestas en ella por cada personaje. Por ser representativa de una ideología fundacional de la identidad nacional estadounidense, “Thanksgiving” tiene un gran peso simbólico en el cuento. El día feriado y la cena simbólica marcan un tiempo/espacio ritual mediante los cuales se re-actualiza la celebración de la sobrevivencia del primer invierno de las colonias. Como tiempo/espacio ritual, la celebración representa tanto un hecho del presente como una suspensión del presente, ya que se posterga toda actividad cotidiana. Vista desde esta perspectiva, la fiesta representa la ritualización del acto de tomar una conciencia de identidad nacional específicamente norteamericana- y a la vez confirma el vivir dos espacios temporales distintos simultáneamente. Este tiempo ritual también se puede entender como un período liminal, un espacio temporal marcado tanto por su fluidez e indeterminación como por su no pertenecencia a lo puramente material ni a lo puramente simbólico. Considerándolo como etapa transitoria, el período liminal posibilita el movimiento de un espacio/tiempo fijo a otro, a la vez que resiste una definición propia, rígida o fija. ${ }^{9} \mathrm{Al}$ nivel conceptual, el cuento propone lo liminal como un elemento integral de la zona fronteriza ya que varios niveles de éste se ven marcados por la liminalidad: la celebración de Thanksgiving, la etapa pre-adolescente de Gabriela y los múltiples espacios físicos que ocupa Gabriela durante el cuento.

Cuando comienza el cuento, Pepe ha vuelto a la casa de su padre con un pavo marca "Butterball” -típicamente americano- que le compró a su comadre Esperanza, a pesar de saber que Elías se opondrá a la celebración. La objeción de Elías, esperada y temida por Pepe, radica en su compromiso con el período de luto tras la muerte de su esposa: “-¿Qué es eso?- la voz del viejo suena dura, acabada. -Pos dice mi comadre que aquí le manda este pavo. -¡Qué pavo, ni qué la chingada!- explota el viejo. -¿Qué no sabe que todavía estamos de luto? ¿O no le dijiste?” (22). Al igual que el día de “Thanksgiving”, el período de luto representa un espacio temporal ritual, una suspensión de ciertas actividades familiares cotidianas por un período, marcado al nivel social por prácticas específicas, entre ellas: el uso de ropa negra, la celebración de misas para el difunto, la suspención de

\footnotetext{
${ }^{8}$ Aunque no se analizará a fondo en este ensayo, el bilingüismo de este texto y otras obras chicanas/ latinas refleja uno de los sitios de choque o conflicto "local” que caracteriza la zona fronteriza. Una novela que explora no sólo el bilingüismo sino también la traducción como práctica feminista fronteriza es Mother Tongue de Demetria Martínez.

${ }^{9}$ El concepto de lo liminal y el término vienen del antropólogo Victor Turner. Para una discusión de su aplicación a varios temas, véase Victor Turner, From Ritual to Theatre: The Human Seriousness of Play.
} 
bodas y fiestas de cumpleaños, el no bailar y el dejar de escuchar música. Gabriela, por su parte, espera celebrar una fiesta "tradicional”, como las que preparaba su abuela:

Gabriela se asoma por debajo de las piernas de su padre, y al ver el Butterball, pega un gritito de felicidad. Mañana es Thanksgiving y su papi le prometió que iban a tener una fiesta como las que hacía su 'buelita. A ella le va a tocar quebrar los piñones y las almendras con la piedrita del molcajete. (21)

En cierto sentido, Pepe debe realizar el difícil papel de tender un puente no sólo entre los espacios rituales en conflicto, sino también entre el pasado de sus padres y el futuro que le pertenece a Gabriela. En función de ese papel, Pepe revela ser un actor torpe que negocia mal las fronteras que definen esos espacios temporales y las fronteras mantenidas por tradiciones y rituales locales en competencia. El más obvio de sus deslices es su incapacidad de entender el dolor profundo de Elías y su expresión mediante el ritual de luto. La resistencia de Elías no es un rechazo a la fiesta "americana”, al contrario, es evidente que Elías guarda buenas memorias de las mismas fiestas celebradas con su esposa: "El viejo no contesta por el momento. Anda ayudándole a su mujer a escoger el pavo más grandote de la tienda. 'Somos muchos viejo, nadie se va a llenar con ése’” (23). Lo que le molesta a Elías es la falta de sensibilidad por parte de Pepe.

Elías y Pepe están en conflicto porque no pueden resolver paradigmas opuestos del tiempo ritual: el tiempo de la fiesta entra en conflicto con el tiempo de luto. En este caso ninguno de los dos paradigmas se distingue fácilmente por ser un ritual “local” en contra/ oposición a una supuesta fuerza hegemónica de afuera ("global”). Ambos pertenecen a las prácticas regionales del diario vivir del espacio local, como lo muestran las memorias de Elías y como lo revelan las expectativas de Gabriela. Gabriela se imagina la heredera, tras la muerte de su abuela, de los quehaceres preparatorios de la fiesta, sobre todo en su deseo por moler los piñones y las almendras para el relleno. La especificidad local de la fiesta se pone de relieve con el símbolo del molcajete que Gabriela imagina usar para las preparaciones. Un mortero mexicano de origen indígena que sirve para machacar especias y semillas, el molcajete simboliza la cocina/cultura mexicana que Gabriela hereda de su abuela. Sin embargo, al imaginarse como elemento central de la preparación de la cena festiva “norteamericana”, el molcajete de Gabriela revela su identidad híbrida. El conflicto de los espacios temporales forma parte de la tensión fronteriza "local/local”, reflejando la geografía particular de una zona en la cual los conflictos trascienden el espacio cartográfico en el cual se inscribe la separación de los Estados Unidos y la nación mexicana. El conflicto de Elías, Gabriela y Pepe pertenece a una geografía en la que las tradiciones locales revelan una hibridez compuesta de fronteras variables y a veces invisibles. La tensión resulta no de la lucha entre una cultura dominante -norteamericana- y su víctima. Al contrario, la tensión es una de la múltiples expresiones de esta zona fronteriza, híbrida e intercultural cuyas tradiciones y rituales revelan las identidades -también híbridas e interculturales-de sus habitantes. A la vez, esta tensión revela la experiencia del espacio relacional en el cual individuos y/o grupos que comparten la misma región geográfica sin embargo ocupan distintos lugares. En el caso de los protagonistas del cuento, cada uno se ubica en un lugar que es determinado por los factores de edad/generación y género. Cada personaje, 
entonces, enfrenta el choque de las tradiciones en conflicto de acuerdo al lugar que ocupa y a la vez muestra su capacidad o inhabilidad de negociar y navegar los conflictos de esta geografía política, social y cultural.

A pesar de sus buenas intenciones al pensar sólo en Gabriela y querer "hacerle una cena a la niña”, tal vez para continuar una tradición familiar, Pepe no sabe ni qué ingredientes se necesitan para la confección del pavo, como bien lo observa la voz narrativa: "ni compró piñones, ni almendras, ni nada de lo que le ponía su abuela al relleno” (21). Hasta cierto punto, Pepe se muestra en una posición rígida desde la cual no logra resolver las demandas de ser un padre soltero que debe proporcionarle a Gabriela tanto las costumbres de la familia como los conocimientos y los rituales sociales que la preparan para el futuro. En su enojo, Elías acusa a Pepe de abandonar las tradiciones familiares por su propia ambición:

Te gusta de corazón ponerme así. Siempre queriendo ser tan diferente, tan ambicioso. Ya te crees muy gringo, ¿verdad? Desde que te metiste al colegio ese, ya no respetas, ya no te importan las costumbres y ni tu madre te importa. Nomás lo tuyo, lo tuyo todo el tiempo.

Mas no es así. De hecho, Pepe le ha mostrado a Gabriela cuánto valen las tradiciones y su profundo respeto por ellas, sobre todo en la casa del abuelo y en el uso del español. Cuando Gabriela lo saluda en inglés, Pepe la regaña y le recuerda que en la casa de su abuelo se habla sólo español. "Habla español, hija, tu abuelo te va a pegar. - ¿Por qué tengo que hablar 'spañol? This is a free country. -Free or not, young lady, you talk Spanish in this house. It's his house, ¿me entiendes? (20). Pepe está sumamente consciente de los límites y las prácticas “locales” que se deben llevar a cabo en el hogar de Elías: aunque no sea “oficialmente” otro país, el hogar representa un límite lingüístico impuesto por Elías para diferenciarse. No se ha atravesado ninguna frontera nacional; no obstante Pepe tiene absolutamente claro que las fronteras existen y hace todo lo posible por respetar y cumplir estas costumbres "locales" como lo exige su padre.

De manera contraria, Gabriela resiste la frontera lingüística impuesta por su abuelo al insistir que "this is a free country" y cuestionar el tener que hablar español cuando no quiere hacerlo. En Gabriela se revela la internalización de una ideología de libertad e independencia individual que es también un elemento integral de la zona fronteriza, pero que obviamente es incompatible con las expectativas culturales de Elías. Vista desde la perspectiva "nacional" norteamericana, Gabriela refleja precisamente esos valores que representan la "esencia” de lo americano. Para Elías, sin embargo, Gabriela se muestra una “mal” educada que desafía tanto a su papá como a su abuelo.

Pepe, por su parte, se compromete a darle una educación formal a Gabriela con la que Elías probablemente no estaría de acuerdo. Por cierto, Elías le acusa a Pepe de asimilarse por haber ingresado al colegio, e insiste en que Gabriela barra la casa en vez de hacer su tarea como Pepe ciertamente lo hubiera preferido. El hecho es que hay cierta verdad en lo que dice Elías. Pepe tiene ambiciones y su mundo difiere del de Elías, no sólo en el nivel generacional, sino social e ideológico, pues él, al igual que Gabriela, recibe educación formal en inglés. No hay duda que Pepe intenta navegar -por torpe que sea- en las 
complejidades particulares de las tradiciones “locales” fronterizas. De manera contraria, Elías se caracteriza por retroceder a un tiempo imaginario del pasado cuya deseada geografía refleja un terreno "local” simplificado fuera de la realidad histórica:

El abuelo no la ve bien hasta ese momento. Una trenza más arriba que la otra, la nariz chorreada, piernas zambas, las manos en la cintura exactamente como se las ponía su vieja con la escoba recargada en el pecho. -'Ta bueno -murmura el viejo, mostrando sus encías, sus ojos hundidos en un mundo de silencio, en una mujer dura, demasiado dura, pero siempre buena y generosa, sin rencores ni reproches. -'Ta bueno vieja. (24)

Aquí el abuelo ve en la nieta a la abuela. Hay un regreso al pasado por el cual Elías proyecta en la nieta el futuro rol de esposa. Su deseo por una simplicidad imaginada es aparente en los papeles género-sexuales que Elías le impone a Gabriela. El cuento comienza con Elías regañándola por no haber barrido el portal, y pronto pasamos a su rabia al verla comportarse de una forma impropia de una "dama”.

[Gabriela] se echa la maroma con las piernas abiertas y la blusa se le sube hasta el cuello, descubriéndole el pecho pálido y huesudo. -'Hora sí- grita el viejo... -hora sí me la pagas, pocha desvergonzada ésta... Se empieza a quitar el cinturón y la niña sale corriendo a la calle. (19)

Semejante a la perspectiva que adopta hacia Pepe, Elías asume que las “transgresiones” de Gabriela provienen de su identidad "pocha” -el resultado de las complejidades del bilingüismo, la hibridez y la tensión interna de choques “locales/locales” en la frontera. Al llamarla pocha Elías invoca una crítica fuertemente nacionalista a Gabriela, pues "las pochas” representan no sólo esos estadounidenses de ascendencia mexicana que entremezclan el español y el inglés, sino que simbolizan una identidad nacional mexicana podrida, estropeada por el contacto con lo norteamericano. Habría sido más fácil para Elías mantenerse en una geografía imaginada de normatividad nacional, sexo-genérica y lingüística. Al final del cuento Elías se retira al interior del hogar, a un espacio sin fronteras “oficiales” pero seguramente delineado por una imaginada soberanía y marcado por el machismo de Elías, su conservadurismo retrógrado, su hispanofilia y su poder patriarcal.

La geografía del hogar de Elías representa el espacio de la actualización de los conflictos "locales/locales" que permean la zona fronteriza. Los tres protagonistas comparten el mismo espacio físico, pero como ha observado McDowell, los tres habitan lugares muy distintos. Esto ocurre debido a la naturaleza relacional del espacio. Como argumentan McDowell y Okley, "los conjuntos particulares de prácticas sociales conectan lo local a lo regional, o a lo nacional o lo global de formas distintas en distintos casos y para distintos individuos” (5). En estos términos, Elías, Pepe y Gabriela, aunque comparten el mismo espacio -el cuento acontece en el hogar de Elías pero también en la frontera del sur de Texas-, cada uno lo experimenta de forma particular e individual. El lugar, la localidad y las fronteras se someten a cambios y variaciones espaciales resultantes de relaciones diferenciadas. Por motivos distintos ni Pepe ni Elías tienen éxito en la navegación y negociación en un terrento que insiste en el cambio, la fluidez, la contradicción, 
la ambigüedad, la ambivalencia y sobre todo la simultaneidad. En el caso de Pepe, sus acciones revelan un intento sincero de manejar expectativas opuestas, pero termina por experimentar la frustración de una lucha agobiante. Elías, como se ha señalado, abandona el patio y "[s]e mete a la casa, jorobado, sus piernas y sus brazos tiesos como el ocotillo que anda por el desierto. Sus pasos se mezclan al machimbre y ni Pepe ni Gabriela pueden oír el astillar de aquella madera” (25). Esta última impresión sugiere la próxima muerte de Elías tanto como el fin de una generación. Con la figura de Elías también desaparece la geografía del pasado, de espacios claramente demarcados por fronteras nacionales, lingüísticas y genéricas.

De los tres personajes, es Gabriela la que encarna la posibilidad de negociar exitosamente los varios espacios que componen y definen la zona fronteriza. Propongo que tal éxito se relaciona íntimamente con una actualización del papel género-sexual que se define en concordancia con los cambios y las variaciones del terreno geográfico sociocultural. La pre-adolescencia de Gabriela es un elemento importante de su papel y su identidad género-sexual. Debido a la liminalidad y fluidez de esta etapa de su desarrollo -aún no es "mujer" aunque, como se ha mostrado más arriba, sus fantasías juveniles han comenzado a incorporar la auto-imagen de ser la heredera del papel de su abuela. Está suspendida en el precipicio de la adultez, sin embargo guarda un aspecto juvenil y enérgico que la protege del estasis de su abuelo. Es precisamente esta energía, y el movimiento casi constante, que la definen. Gabriela se presenta en las primeras líneas del cuento meciéndose en una hamaca. De ahí se ve dando volteretas sobre las manos y luego haciendo maromas y saltos mortales para su padre (19). Después de ayudar a Pepe a descargar las provisiones, hace un pequeño berrinche cuando su padre la regaña por no hablar en voz baja (21). En una ocasión se le ve barriendo furiosamente en el balcón de la casa de Elías cuando él y Pepe discuten adentro. Al final del cuento Gabriela explota en una rabieta fúrica al luchar con su propia frustración ante la discusión entre su padre y su abuelo. En conjunto, estas imágenes representan una joven vigorosa y plenamente vital. Gabriela no se mantiene callada, en espera de un destino desconocido. Esa vitalidad se contrasta con Elías y Pepe -el primero duerme intermitentemente en su sillón o camina por la casa arrastrando los pies, y el segundo se arrodilla frente el refrigerador, humillado por la culpa que siente por haber aceptado el pavo. Frente a ellos, Gabriela encarna agilidad y movilidad, la vitalidad, el momento, y la capacidad de transformación y desarrollo.

Es más, en contraste con Elías y Pepe, Gabriela revela su capacidad de adaptación a un número de roles distintos. Elías, un viudo anciano que se ha exiliado al país de su propia imaginación, ni siquera trata de asumir papeles que transgreden los límites sexo-genéricos tradicionales. Cuando se necesita a alguien que barra el patio, Elías insiste en que Gabriela lo haga a pesar de que ella debería hacer su tarea. No es imaginable que el propio abuelo podría hacerlo. Pepe, aunque es aparente que sinceramente intenta asumir nuevos y distintos papeles -el ejemplo de la celebración de Thanksgiving es el más obvio- queda claro que para él, realizar los múltiples papeles de padre y madre, padre e hijo, estudiante y trabajador es agobiante. A través de todo el cuento Pepe muestra ser el personaje más obligado a cumplir expectativas contradictorias, el más frustrado y el más oprimido por las relaciones restringidas que experimenta en su ambiente. Gabriela muestra tanto su capacidad de cumplir con los quehaceres domésticos, como su habilidad de tener éxito en 
los estudios académicos. Aunque ambos, Pepe y Gabriela, son bilingües, sólo Gabriela expresa sus propias reglas sobre dónde y cuándo hablará cada idioma. Ella es flexible, enérgica, libre de las trabas de una identidad determinada por puntos fijos en el mapa de expectativas socio-culturales. Es interesante que Gabriela es la única protagonista femenina activa en el cuento. Las otras dos mujeres mencionadas -su abuela y Esperanza, una amiga de la familia-forman parte de un trasfondo narrativo pero nunca se convierten en actores funcionales de la historia. El cuento le otorga un lugar privilegiado hasta cierto punto, puesto que Gabriela nunca se ve nesecitada de interrogar los papeles de otras mujeres ni las ideologías culturales, políticas y sociales que se transfieren de una generación femenina a otra. En este contexto, Gabriela vive y actualiza su papel sexogenérico desde esta ubicación fluída, móvil y de ahí promete navegar exitosamente los conflictivos espacios sociales locales sin necesidad de anclaje.

Las relaciones espaciales que establece Gabriela a lo largo del cuento, junto con los espacios en que se localiza, revelan una movilidad que sugiere aún más la fluidez que las críticas chicanas (Saldívar-Hull, Anzaldúa y Sandoval) han teorizado como características de una práctica feminista fronteriza. A principios del cuento, Gabriela se encuentra en una serie de espacios liminales. Inicialmente se mece en una hamaca, suspendida entre el cielo y la tierra, simbólicamente independiente de los dos y siempre perteneciente a ellos. Más tarde hace una voltereta sobre las manos, subvirtiendo así la relación normativa de la fuerza de gravedad -con los pies al aire, las manos sobre el suelo. Las imágenes físicas, y las “locaciones” de Gabriela representan un reto a las posibilidades restringentes del espacio. Aún cuando le acompaña a Pepe a la cocina rehusa bajar la voz y mantenerse callada, de esa forma logra imponerle su propia voluntad al espacio doméstico. En las últimas escenas del cuento, Gabriela busca refugio en el balcón, en los límites del hogar de Elías, cuando discuten los hombres. Los observa desde la periferia que ella ha escogido, manteniéndose fuera del conflicto con cierta seguridad y protección. En todas estas escenas, la ubicación de Gabriela refleja la variedad de posiciones fronterizas que se deben navegar y negociar. Para tener éxito en estos espacios hay que mantener una cantidad de fluidez y liminalidad para así ser capaz de navegar en las normas sociales restringentes, y para tener la “competencia” de poder localizarse en los márgenes del conflicto.

Es en las últimas escenas del cuento en las que Gabriela realiza su relación espacial más simbólica. Esta se da en voz del narrador cuando se hace aparente que Pepe se rendirá a las demandas de Elías,

Sube al porche y empieza a barrer desesperadamente, su cuerpo girando como trompo. Levanta olas de polvo a su alrededor y luego luego le da comezón y le sale agua de la nariz. Puede oír que ellos todavía están discutiendo en la cocina, pero ya no quiere escuchar qué dicen. -Pos, ¿qué estás haciendo, niña? Brinca al oír la pregunta de su padre. Para de barrer, y las oleadas de tierra se vuelven a sentar sobre las tablas chuecas del porche. (24)

Aquí Gabriela se envuelve en una fortaleza de polvo, construyendo su propio espacio -uno que le permite tener acceso a los acontecimientos que la rodean, pero que al igual le proporciona el asilo- un refugio, un lugar propio. En el porche, en los límites del hogar de su abuelo, en la zona fronteriza del sur de Texas, una mujer joven toma una posición 
de sujeto activo ejerciendo su propia voluntad al echar mano a las herramientas -una humilde escoba y su propia energía física- para construirse y definirse por sí misma, por sus propios términos y en un lugar propio.

"El pavo” concluye sin resolución alguna. Elías desaparece mientras Pepe y Gabriela se abrazan tras el último, frántico berrinche de Gabriela. El pavo permanece en la bolsa de papel. No hay indicios que se le devolverá a Esperanza. Tampoco queda claro si formará parte de una futura celebración. Lo claro es que fronteras de toda índole se han atravesado, transgredido, re-definido y re-inscrito. No hay desenlace, no hay solución. En muchos sentidos la ambigüedad e irresolución del final del cuento refleja la misma zona fronteriza donde, como observa Néstor Canclini, “existen alambres rígidos y alambres caídos” (26061). Canclini hace referencia no sólo a los alambres físicos y materiales que se instalan en los límites de las naciones, sino también a los alambres que se introducen a través de interacciones individuales con el espacio en dadas relaciones de poder. El ir y venir, el fluir de los límites fronterizos produce nuevos espacios que pueden o no convertirse en lugares permanentes del terreno o del espacio social siempre -eso sí- regido por la hibridez y la contradicción. Las teorías de la nueva geografía locacional, con su énfasis en la naturaleza relacional del espacio, iluminan en "El pavo" una práctica feminista chicana "locacional/ posicional” que libera al sujeto no sólo en conflictos “locales/globales” sino también, y tal vez más importante, en los mismos choques “locales” de la zona fronteriza.

\section{BiBLIOGRAFÍA}

Anzaldúa, Gloria. Borderlands/La Frontera: The New Mestiza. San Francisco: Spinsters/ Aunt Lute, 1987.

Benhabib, Seyla. Situating the Self: Gender, Community and Postmodernism in Contemporary Ethics. London: Routledge, 1992.

Calderón, Héctor y José Saldívar (eds.). Criticism in the Borderlands: Studies in chicano Literature, Culture, and Ideology. Durham: Duke University Press, 1991.

Cooper-Alarcón, Daniel. The Aztec Palimpsest: Mexico in the Modern Imagination. Tucson: University of Arizona Press, 1997.

Friedman, Susan Stanford. Mappings. Princeton, NJ: Princeton University Press, 1998.

García Canclini, Néstor. Hybrid Cultures: Strategies for Entering and Leaving Modernity. Christopher L. Chiappari y Silvia L. López, trad. Minneapolis: University of Minnesota Press, 1995.

Gaspar de Alba, Alicia. The Mystery of Survival. Tempe, AZ: Bilingual Press/Editorial Bilingüe, 1993.

Gómez-Peña, Guillermo. The New World Border: Prophecies, Poems, and Loqueras for the End of the Century. San Francisco: City Lights Books, 1996.

Grewal, Inderpal y Caren Kaplan. Scattered Hegemonis: Postmodernity and Transnational Practices. Minneapolis: University of Minnesota Press, 1994.

Hicks, Emily. Border Writing: The Multidimensional Text. Minneapolis: University of Minnesota Press, 1991.

Martínez, Demetria. Mother Tongue. Tempe: Bilingual Press, 1994. 
McDowell, Linda. Gender, Identity and Place: Understanding Feminist Geographies. Minneapolis: University of Minnesota Press, 1999.

Okely, Judith. Own or Other Culture. London: Routledge, 1996.

Reboledo, Tey Diana. Woman Singing in the Snow: A Cultural Analysis of Chicana Literature. Tucson: University of Arizona Press, 1995.

Rose, Gillian. Feminism and Geography: The Limits of Geographical Knowledge. Cambridge: Polity Press, 1993. y Steve Pile (eds.). Mapping the Subject: Geographies of Cultural Transformation. London: Routledge, 1995.

Saldívar, José David. The Dialectics of our America: Geneology, Cultural Critique, and Writing History. Durham: Duke University Press, 1991.

Saldívar-Hull, Sonia. Feminism on the Border: Chicana Politics and Literature. Berkeley: University of California Press, 2000.

Sandoval, Chela. "Mestizaje as Method: Feminists of Color Challenge the Canon”. Living Chicana Theory. Carla Trujillo, ed. Berkeley: Third Woman Press, 1998. 352-370.

Tabuenca Córdoba, Socorro. Mujeres y fronteras: una perspectiva de género. Chihuahua: Instituto Chihuahuense de Cultura, 1998.

Turner, Víctor. From Ritual to Theatre: The Human Seriousness of Play. New York: Performing Arts Journal Publication, 1982. 